\title{
Assessment of the adaptability of Dutch breeding Holstein cattle to the conditions of the steppe zone of the Central Ciscaucasia
}

\author{
Zh.H. Kurashev ${ }^{1, *}$, V.M. Gukezhev ${ }^{1}, O . O$. Getokov $^{2}$, M.Kh. Zhekamukhov ${ }^{1}$, and Z.M. \\ Aisanov $^{2}$ \\ ${ }^{1}$ Kabardino-Balkarian Scientific Center of the Russian Academy of Sciences, KBR, Nalchik, Russia \\ ${ }^{2}$ Kabardino-Balkarian State Agrarian University named after V.M. Kokova, KBR, Nalchik, Russia
}

\begin{abstract}
The analysis of homeostasis was carried out on the basis of hematological blood parameters of highly productive Holstein cattle (average milk yield is $9300 \mathrm{~kg}$, robotic farm, $\mathrm{n}=106$ ) which made it possible to establish average indicators and their variability in new, to a certain extent, extreme conditions. Analysis of the results obtained indicates that contrary to the established opinion about the relative stability of indicators of the hematological composition of blood, the organism of imported animals is experiencing rather strong overloads as evidenced by the high degree of variability of different blood elements. Some animals lose their fatness dramatically, even against the background of an average nutritional value of a balanced daily diet, sufficient for a milk yield of 30$33 \mathrm{~kg}$ of milk. High variability was noted in the number of lymphocytes (lim) - 64.3, medium cells (Mid) - 56.5 and granulocytes (Gran) - 42.5 percent. More stable indicators for the average volume of erythrocytes 5.3, the content of hemoglobin in erythrocytes $(\mathrm{MCH})-8.7$, the concentration of hemoglobin (HGB) - 9.1 and hematocrit number (NBT) 10.6 percent.
\end{abstract}

\section{Introduction}

Dairy farming in Russia along with grain production is the main branch of the agricultural sector providing a daily turnover of funds which is very important for the life of any business entity. Apparently, there is no need to prove to anyone the importance of organic products $[1,2]$.

It should be noted that against the background of a fairly stable increase in cow productivity indicators, the introduction and development of new technologies, many economic enterprises of various forms of ownership, using the genetic potential of Holstein cattle selection from different countries, achieved record productivity indicators which is very important to consolidate. However, record milk yields at any cost today are not for business, no longer an argument for the market. With all the advantages of the Holstein breed, it has two important disadvantages: low reproductive quality and a sharp decline in

\footnotetext{
* Corresponding author: kurashev-j@mail.ru
} 
productivity starting from the third lactation [3]. The results of our research give some hope that animals of local selection while maintaining high productivity are distinguished by greater vitality.

Most scientists testify that all living things maintain the relative stability of the indicators of the physiological composition of blood using for this all the available reserves of the body [4-6].

Relevance. The issues of adaptation of imported livestock to various natural and climatic conditions, the preservation and implementation of the high genetic potential of productivity are due to the stability of the hematological composition of the blood. In this regard the establishment of the dynamics of the main elements of blood such as a reaction of metabolic processes in new conditions of feeding and maintenance is very urgent to manage the adaptation process.

Purpose of the study: to establish the reaction of the body of animals to new conditions, the reasons for the shift in the morphology of individual elements, ways to stabilize cow homeostasis taking into account the physiological state of cows.

\section{Research material and methods}

Blood was taken from animals in compliance with the rules of asepsis and antiseptics. Before the start of blood collection the place of blood sampling was carefully cut and wiped with a cotton swab moistened with alcohol-ether. Blood was collected in vacuum tubes with an anticoagulant with EDTA marking, Trilon B (ethylenediaminetetraacetate). EDTA promotes the creation of chelating compounds with IV blood coagulation factor $(\mathrm{Ca} 2+)$, with the formation of soluble highly stable complexes. (Fig. 1.)

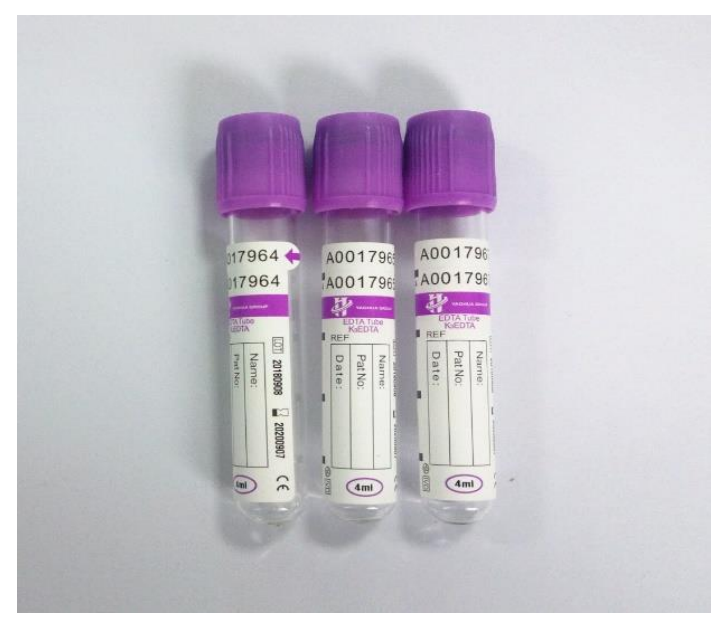

Fig. 1. Vacuum test tube.

Instead of conventional butterfly catheters sterile disposable double-sided needles with a visual chamber closed with protective pink caps on both sides were used as a needle. 

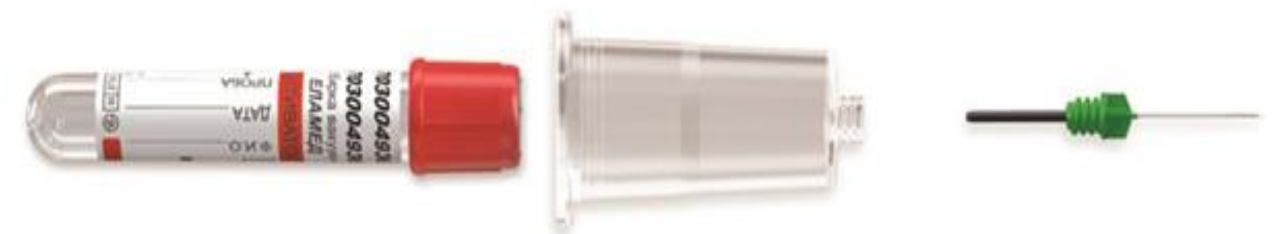

Fig. 2. Sterile disposable needle with visual chamber.

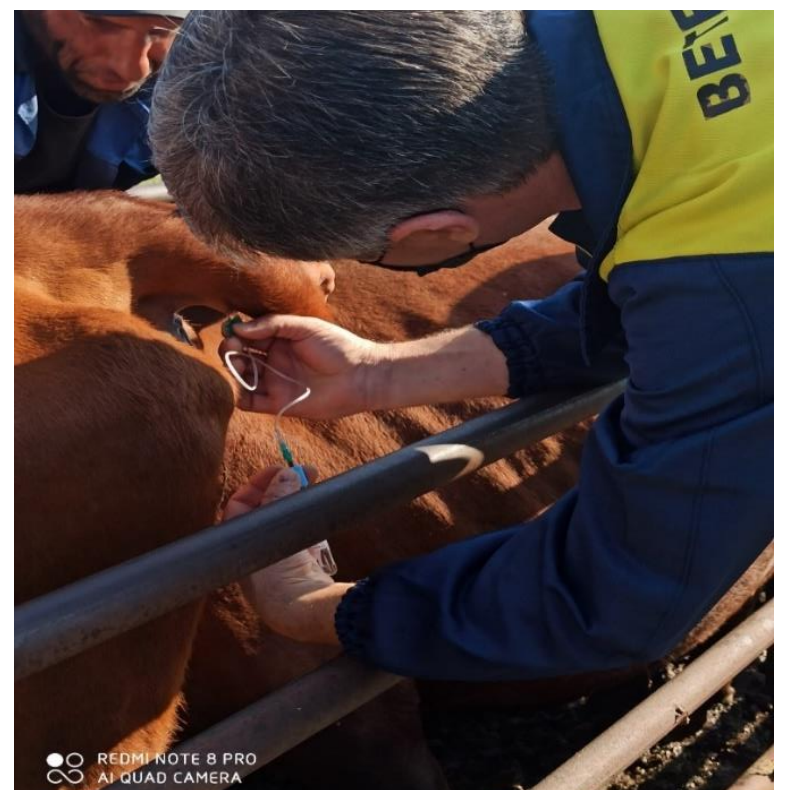

Fig. 3. Blood was drawn from the tail artery of the cows.

Fresh blood was delivered within 2 hours to the laboratory of molecular selection and biotechnology KBSC RAS. The analysis of blood samples was carried out using the Gemalight 1270 hematological analyzer designed to measure the mass concentration of hemoglobin by the photometric method and the concentration of cells of the leukocyte, erythrocyte and platelet groups by the conductometric method.

Using this device allows you to determine within 60 seconds the following indicators which are based on the results obtained for 21 parameters of human and animal blood. In this work we examined the blood of animals according to 9 hematological parameters:

- the absolute number of leukocytes (WBC) - 109/1;

- the absolute number of lymphocytes (LIM \#) - 109 / 1;

- the absolute number of "average" cells (MID \#) - 109 / 1;

- the absolute number of granulocytes (GRAN \#) - 109/1;

- the absolute number of erythrocytes (RBC) - $10^{12} / 1$;

- concentration of hemoglobin (HGB) - g / 1;

- hematocrit number (HCT) - \%;

- average erythrocyte volume (MCV) - vial;

- the average content of hemoglobin in the erythrocyte $(\mathrm{MCH})-\mathrm{pg}$. 


\section{Research results and their discussion}

The study of animal blood is both diagnostic and a clinical indicator of their general physiological state. It should be noted that for an experienced practitioner, even a visual assessment of the general condition of fatness, behavior, food intake, chewing gum, the state of the skin and other elements without any special errors, let diagnose the physiological state of animals. Naturally these conclusions must be confirmed by the appropriate clinical indicators for diagnosis [7].

As it was noted the purpose of the study was the results obtained on the basis of the morpho-hematological blood test which reflect the degree of reaction of the imported animals by the end of the second year of their use in the conditions of the Central Ciscaucasia.

The results obtained (Table 1) indicate that the period of stay in the new climatic, technological, and forage conditions was relatively insufficient to stabilize homeostasis as evidenced by the high variability of different blood elements.

The analysis shows that with an average daily milk yield of $26.7 \mathrm{~kg}$, the difference between the maximum $(57.0 \mathrm{~kg})$ and minimum $(7.3 \mathrm{~kg})$ value of the average daily milk yield of $45.7 \mathrm{~kg}$, more over when the coefficient of variability is $59.0 \%$, the level and type of feeding can be considered the main "cause" of the corresponding high variability of individual blood elements. We do not exclude such a possibility although the ration of feeding cows is quite clearly balanced, in terms of its nutritional value it provides an average daily milk yield per herd (a robotic farm for 120 dairy cows) in the range of 30-33 $\mathrm{kg}$ of milk. At the same time an individual assessment of cows shows that both maximum and minimum values of various blood elements are inherent, in most cases, in animals of the middle modal productivity class. Naturally low-productivity animals are of little interest for breeding, but their responses to conditions are important to ensure norms and variations of the analyzed indicators.

Table 1. Hematological parameters of Holstein cows

\begin{tabular}{|c|c|c|c|c|c|c|c|c|c|}
\hline & WBC & RBC & $\begin{array}{c}\text { LIM } \\
\#\end{array}$ & $\begin{array}{c}\text { GRAN } \\
\#\end{array}$ & MID \% & HGB & HCT & $\overline{M C V}$ & $\overline{\mathrm{MCH}}$ \\
\hline$\stackrel{凶}{\stackrel{\varpi}{g}}$ & 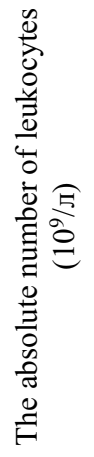 & 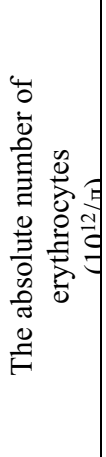 & 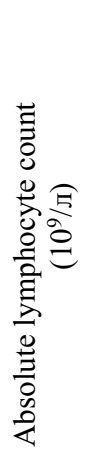 & 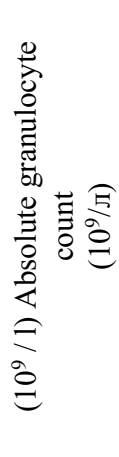 & 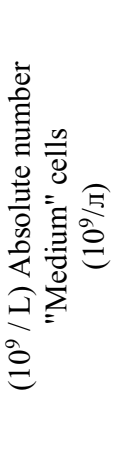 & 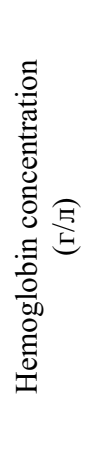 & 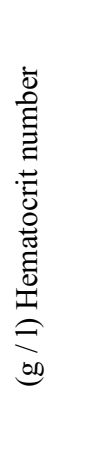 & 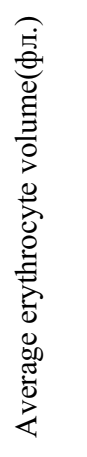 & 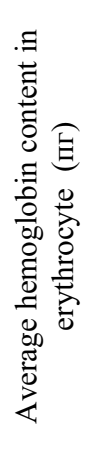 \\
\hline 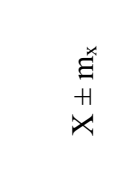 & 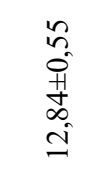 & $\begin{array}{l}\infty \\
0 \\
0 \\
\text { H1 } \\
\text { n. } \\
0\end{array}$ & 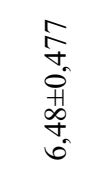 & 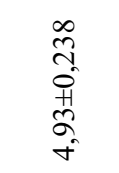 & 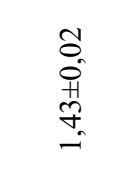 & 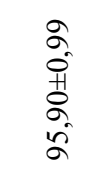 & 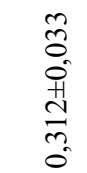 & $\begin{array}{l}0 \\
\text { m. } \\
\text { H } \\
m \\
\text { gे }\end{array}$ & $\begin{array}{l}\tilde{n} \\
n \\
0 \\
0 \\
\infty \\
n \\
n\end{array}$ \\
\hline $\begin{array}{c}\text { Max. } \\
\text { meaning }\end{array}$ & 38,53 & 7,64 & 26,28 & 11,43 & 5,55 & 118 & 0,386 & 57,5 & 19,9 \\
\hline
\end{tabular}




\begin{tabular}{|c|c|c|c|c|c|c|c|c|c|}
\hline $\begin{array}{c}\text { Min. } \\
\text { meaning }\end{array}$ & 4,34 & 4,30 & 1,08 & 1,55 & 0,42 & 72 & 0,224 & 45,0 & 13,0 \\
\hline Difference & 34,19 & 3,34 & 25,20 & 9,88 & 5,13 & 46 & 0,162 & 12,5 & 6,9 \\
\hline $\mathrm{Cv}$ & 37,8 & 11,73 & 64,3 & 42,5 & 56,5 & 9,1 & 10,6 & 5,3 & 8,7 \\
\hline
\end{tabular}

According to the results of studies out of 9 basic blood elements a rather high variability was noted in the absolute number of lymphocytes $(\mathrm{Lim}=64.3 \%)$, medium cells $(\mathrm{Mid}=$ $56.5 \%$ ) and granulocytes ( Gran $=12.5 \%$ ), more than three times the variability of other elements and the number of leukocytes $(\mathrm{WBC}=37.8 \%)$. The variability of erythrocytes $(\mathrm{RBC}=11.73)$, hematocrit number $(\mathrm{HCT}=10.6)$, hemoglobin concentration $(\mathrm{HGB}=9.1)$, average hemoglobin content in erythrocytes $(\mathrm{MCH}=8.7)$ and average erythrocyte volume can be noted relatively stable. (MCV $=5.3 \%$ ).

The difference between the extreme options (limit) for the three indicators of high variability in comparison with the average was respectively 3.9; 3.6 and 2 times which indicates the presence of certain reasons causing such jumps in individual blood elements. Of course, both the average and the indicators of individual individuals do not always determine the state of the herd, however, they give rise to the need for a more thorough analysis of all components and, first of all, feeding. It should be noted that robotic farms actually use the same level of feeding regardless of the lactation phase. This approach is accompanied by overfeeding of some cows, starting from the end of the second and the entire third phase of lactation whose milk yield is below the herd average. Experience shows that overfeeding is more harmful than moderate feeding. It is with this that we associate a high coefficient of variability of the average daily milk yield, on the day of blood sampling, equal to 59.0 percent, and the fact that extreme variants of the analyzed blood elements are inherent in animals, in most cases with milk yield below the average for the herd.

\section{Conclusions}

Adaptation process of Holstein breed cows to natural and climatic conditions of KBR steppe zone has been continuing. It can be seen by the rather high variability of the absolute number of lymphocytes, middle cells and granulocytes. As for the rest of the studied indicators, certain stability has been achieved: Technology of dairy cows joint keeping on a robotic farm regardless to productivity does not allow regulating the feeding rate quite clearly during milking which needs to be established when analyzing cow homeostasis.

\section{References}

1. R.M. Mudarisov, G.R. Akhmetzyanova, I.N. Khakimov, Bulletin of the Bashkir State Agrarian University, 4, 67-73 (2019)

2. O.O. Getokov, Biological characteristics and productive qualities of Holstein cattle in Kabardino-Balkaria (VNIIplem. p. Lesnye Polyany, Mosk. region, 2000)

3. M.I. Uzhakhov, O.O. Getokov, Z.M. Dolgieva, Dairy and beef cattle breeding, 2, 3032 (2016)

4. O.I. Vyatkina, M.P. Potapnev, O.V. Krasko, Hematology and Transfusiology, 3 (65), 251-262 (2020)

5. E.V. Matosova, B.G. Andryukov, Hematology and Transfusiology, 4 (62), 223-229 (2017)

6. V.S. Kozyreva, A.N. Shilova, O.V. Skoda, Hematology and Transfusiology, 1 (64), 6672 (2019) 
7. A.F. Shevkhuzhev, I.K. Taov, O.O. Getokov, E.R. Gosteva, Research Journal of Pharmaceutical, Biological and Chemical Sciences, 8 (6), 591-596 (2017) 